Ethiopian Journal of Environmental Studies \& Management 10(5): 618 - 628, 2017.

ISSN:1998-0507

doi: https://dx.doi.org/10.4314/ejesm.v10i5.6

Submitted: March 08, 2017

Accepted: June 28, 2017

\title{
FACTORS INFLUENCING ROAD TRAFFIC DELAY: DRIVERS' PERSPECTIVES AND LOSS OF MAN-HOUR ALONG LAGOS-ABEOKUTA EXPRESSWAY, LAGOS, NIGERIA
}

\author{
*BAKO, A.I. ${ }^{1}$ AND AGUNLOYE, 0.0.2 \\ ${ }^{*} 1$ Department of Urban and Regional Planning, University of Ilorin \\ ${ }^{2}$ Department of Urban and Regional Planning, University of Lagos
}

\begin{abstract}
This study examined drivers' perception of road traffic delay attributes and factors influencing road traffic delay with a view to assessing loss of man hours along LagosAbeokuta Expressway. This view translated to policy statements that can tremendously reduce the road traffic delay in the study area. Primary data were collected through questionnaire administration, traffic volume survey and direct field observation while the secondary data were obtained from past relevant journals, textbooks among others. The sample frame evolved from an average of 3 day traffic volume survey, which translated into 17,647 drivers between $7 \mathrm{am}-7 \mathrm{pm}$ in the study area. The sample size was 117 (0.007\%) as the purposive sampling technique was adopted. The frequency tables and likert scale outputs were adopted for data analyses. The study found that most drivers along this road were majorly (75.2\%) young educated working adults while the trips made accounted for the concentration of work and after-work trips along this road. The study revealed that traffic delay along the road was largely due to indiscreet use of bus-stops, bad roads condition, drivers' recklessness with DAl values of $4.70,3.77$ and 3.41 respectively using a 5 Point Likert Scale. This study established that a total of 2,920 'manhours' was lost annually on this road as the daily accumulated estimate for man hour loss was estimated as 8 hours per day. The strict enforcement and monitoring of proper usage of bus-stops and prompt rehabilitation of bad roads are needed among other recommendations.
\end{abstract}

Key Words: Road Traffic Delay, Drivers' Perspectives, Man-Hour Loss

\section{Introduction}

The world today has continued to witness a tremendous geometric growth in human population, with a great influx of people migrating into the cities to settle in search of opportunities. This has increasingly put pressure on mobility which is key to development and constitutes the driving force of all human activities; economic, social or political (Oyesiku, 2002). The need for linking places, settlements and land uses creates a rising demand for transportation facilities for commuting people and distribution of goods and services, as well as an increase in the number of vehicles and road users.

*Corresponding Author: Bako, A.I.

Email: alibbako@yahoo.com 
Besides, there is no proportional increase in number of roads or transport routes to match the teeming populace. This results in exertion of more pressure on the existing transport channels beyond their designed capacity of use, leading to delay in traffic and traffic congestion. This has led to difficulty in navigating within and outside the city as it is typically seen in the mega-city of Lagos, which is reflected in the increasing bumper-to-bumper traffic delay experienced during the peak hours of $6.30 \mathrm{am}-11.30 \mathrm{am}$ and $3.00 \mathrm{pm}-7.30$ $\mathrm{pm}$ in the mornings and evenings respectively (Asiyanbola et al., 2012). Traffic delay is defined as a condition of traffic delay (i.e., when traffic flow is slowed below reasonable speeds) because the number of vehicles trying to use a road exceeds the design capacity of the traffic network to handle it.

Downs (2004) defined traffic congestion as the situation when traffic is moving below the designed capacity of the roadway. Kombs (1988) maintains that the situation is usually caused by the rapid growth in motor vehicle use with less than corresponding improvement in the road network and related facilities, the poor structural pattern of roads especially in the traditional areas of cities and the unplanned growth and haphazard land-use distribution.

Business and commercial distributions depend on urban transportation systems for the mobility of its customers, employees and suppliers. However, the poor urban transport scenery causes delays which leads to loss of man-hours. A man-hour is the total amount of work/labour performed by an average worker in one hour, without taking into account breaks generally required such as for rest, eating or other bodily functions. Oni (1992) identified traffic problems as multi-dimensional and bewildering, highlighting the countless man-hours lost in traffic congestion and the wastefulness of human energy and motor fuel as factors that have a serious impact on the economic efficiency, productivity and social performance of the area. Effective transportation system is significantly important in sustaining economic growth in contemporary economies as it links different parts of the country and the global world (Eddington, 2006). The factors which contribute to the traffic problem include the poor geographical location of the city, coupled with inadequate and inefficient transport activities, irrational behaviour of drivers and acute growth in the level of car ownership. Other factors responsible for traffic congestion in Lagos mega-city and in Nigerian cities in general are: inadequate parking spaces, erratic public transport, over-reliance on road and indiscipline among the motorist (Adedimila, 1981; Oyesiku, 2002).

The study area is one of the major roads in Lagos State, being an inter-state Road, linking Lagos and Ogun states as well as other communities such as Agege, Ijaiye, Ipaja, Igando, Ikotun and Ikeja. Solving the challenge of traffic delay on this road appears challenging as the area keeps developing, thereby pulling more traffic to the area. This study focused on assessing the loss of man-hour experienced by drivers with a view to reducing road traffic delay within the study area. 


\section{Literature Review and Conceptual Framework}

\section{Traffic Delay Pattern on Urban Roads}

Several researchers have made attempt at studying the pattern of traffic delay on urban roads so as to be able to proffer solutions to the ever increasing problem of traffic congestion on urban roads. Banjo (1984) identified two major types of traffic congestions which are recurrent congestion and non-recurrent congestion. Recurrent congestion is caused by rapid growth in population, urbanization and a tremendous increase in car ownership and use. It occurs majorly at peak periods when there is a high influx of vehicles on the road, thereby considerably slowing down traffic speed and increasing commuting time of individual commuters. It could also occur at off-peak periods and during weekends. Non-recurrent congestion is usually caused by random, unique and spontaneous occurrences or obstructions or traffic incidents such as vehicle break downs, vehicle accidents or traffic crashes and weather disturbances which are unpredictable. Traffic delay usually occurs at intersections on arterial roads; the more the intersections and inlets into the expressway, the more likely there will be the chance of traffic congestion. As vehicles slow down to make diversions, such as a U-turn, and wait to have clear entrance before driving through, this causes other vehicles to slow down and eventually creates a long chain of traffic.

Olak et al. (2016) studied traffic pattern of drivers in 5 urban cities tracing mobile phones of respondents to study routing and travel pattern of commuters. He observed that the ratio of road supply to travel demand explained the percentage of total time lost in congestion. In other words, as travel demand increased without commensurate increase in road or infrastructure supply, the greater the traffic congestion or time lost in traffic congestion.

\section{Causes of Traffic Congestion on Urban Roads}

Transportation demands and road traffic continue to rise within Lagos, leading to increasing congestion and delays (go-slow) occasioned by greater access to cars (as purchasing power of the middle-income classes rises), access to credit, population growth and large supply of used cars; as well as poor quality of driving especially by drivers of public commercial vehicles or transit vehicles (LASMEPB, 2013). Traffic congestion is also caused by the recklessness of Lagos road users, the impatient nature and the lack of respect for traffic rules and regulations, due to outright negligence and sometimes lack of knowledge of traffic signs and symbols.

Cities are locations having high levels of accumulation and concentration of economic activities and are complex spatial structures that need the support of transport systems to work efficiently. The bigger the city, the more complex it is, and also the more potentials there are for disruptions if the complexity is not effectively managed (Rodrigue, 2013).

Odeleye (2008) postulated that the traffic congestion problem of Lagos is as a result of the imbalance in the supplydemand and the road traffic environment. The imbalance emanates from the geometric increase in the level of motorization and population of the city, without a commensurate level of growth in the provision of road traffic 
infrastructure, as well as multimodal mass transit facilities.

\section{Loss of Man Hour on Urban Roads}

Man hour loss or traffic time loss occurs when there is excess time spent than normal commuting time, as a result of an occurrence which inhibits free flow of traffic .i.e. when there is a delay that prevents free movement of traffic, causing commuters to spend longer time in covering a distance that would otherwise have taken a shorter time to cover (Olagunju, 2013). Individuals' willingness to save time at a higher cost of transportation is a complex network as the monetized value of time varies to individuals, and commuters have different levels of significance of environmental variables. Today, most economists believe that economic value is subjective and dependent on individual preferences (Mabrouk and Abdennadher, 2016).

Man hour loss is one of the several effects of traffic delay or congestion, which causes commuters' physical loss in the waste of useful time, economic loss in higher cost of commuting, significant in the purchase of higher volumes of motor vehicle fuel and higher cost of vehicle maintenance; health defects from the release of energies, and poisonous gaseous emissions from vehicles which

$$
\frac{2+4+5+14+35+62+3+2+2}{9}=\frac{129}{9}=
$$

where carrying capacities are given as Motorcycles $=2$; Tricycles $=4$; Cars $=5$; Mini buses $=14$; Buses $=25 ;$ BRT $=48$; Trucks $=3 ;$ Vans $=2$ and Tankers $=2$. The average traffic volume from the toll gate is given as 19,153, and 16, 140 for traffic to the toll gate respectively. This gives the average total traffic volume along this road as 17, 647 daily. This pollutes the environment. However, a factor behind this trend is related to residential affordability as housing located away from the central area(where majority of employment are) is more affordable, causing commuters to trade time for housing affordability (Rodrigue, 2013).

\section{Methodology}

The data types used for this study were Data on travel and delay patterns which included purpose of trip, time of trip, mode of travel, frequency of travel; Data on causes of traffic delay, which included natural factors, environmental factors, human factors and Data on estimated loss of man-hour, which included length of period of delay, cost of trip, extracost/damages incurred as a result of time loss. The sample frame focused on drivers and riders along Lagos-Abeokuta expressway. These drivers and riders operate motorcycles, tricycles, cars, commercial buses (mini \& standard), BRT buses, trucks, vans and tankers. The sample frame for this study represented the average of the carrying capacity of all vehicular types captured in the traffic volume survey multiplied by the average of the total number of traffic volume recorded in 3 days. This is expressed mathematically as;

value is adopted as the sample frame for this study.

The sample size was obtained through the sample size formula developed by Taro Yamane (1967). A confidence level of $95 \%$ and margin error of $5 \%$ is assumed for the study. Due to limitations and constraints in conducting the study and capturing respondents, and 
with respect to the expected duration for completion of the research, $30 \%$ of this sample were selected for questionnaire administration, this translates to the number of respondents as $3 / 10 \times 391=$ 117 respondents as 116 were completed and returned for analysis. This study utilized purposive sampling technique while the sampling procedure covered the reconnaissance, identification of the study area, selection of bus stops and conduct of interview with drivers at the selected bus stops. The techniques used in the analysis of data included frequency tables, cross tabulation tables and likert scale outputs.

\section{Results and Discussion}

Traffic Characteristics of Respondents (Drivers)

\section{Delay Frequency}

Results as shown in Table 1 revealed that $79 \%$ representing 92 respondents experienced road traffic delay everyday along this road; 15 respondents representing $12.9 \%$ experienced traffic sometimes, which means there are periods when there is free flow of traffic and there are periods when there is traffic congestion; 4 respondents representing $3.5 \%$ experienced road traffic delay during weekends and 5 respondents representing $\quad 4.3 \% \quad$ occasionally experienced road traffic delay in the study area. The observed delay pattern depicts that traffic occurs almost every day as it was further revealed that it is experienced on the lane from the toll gate during the morning peak period, while traffic to the tollgate experiences free flow. This might be due to accumulated work trips to Ikeja CBD and other parts of Lagos. At the evening peak period, there is a reversal in the traffic pattern as congestion shifts to the tollgate-bound lane, when workers and businessmen are returning from work, leaving the lane of traffic from the toll gate mostly free.

Table 1: Frequency of Delay

\begin{tabular}{lll}
\hline Frequency of Delay & Frequency & Percent $(\%)$ \\
\hline Everyday & 92 & 79.3 \\
Sometimes & 15 & 12.9 \\
Weekends & 4 & 3.4 \\
Occasionally & 5 & 4.3 \\
Total & 116 & 100.0 \\
\hline
\end{tabular}

\section{Traffic Delay Hotspots}

Based on the research findings from the study area, the following notable locations (as recorded by respondents) were highlighted as traffic delay hotspots i.e. points of congestion or delay along the road.
i. Abule-egba
ii. Cement
iii. Ikeja-Along
iv. Ile-epo
v. Iyana-Dopemu
vi. Iyana-Ipaja
vii. Toll gate (Sango, Ota)

As revealed from the pilot survey, the aforementioned locations were highlighted as traffic delay hotspots, certain locations appeared predominant, which signifies that they are core areas of major concern. These areas included Abule-egba, Iyana-ipaja, Iyana-dopemu, and toll gate.

\section{Traffic Delay Magnitude}

Results showed in Table 2 that respondents' opinion about the intensity/ magnitude of traffic delay on this road has a total of $76 \%$ of respondents, who experienced long/heavy traffic delay along this road, while $24 \%$ experienced short/light traffic delay. This goes to say that there are 0.76 chances of 
experiencing heavy traffic on this road, and 0.24 chances of experiencing light traffic travelling along this road.

Table 2: Magnitude of traffic delay

\begin{tabular}{lll}
\hline Magnitude of Traffic Delay & Frequency & Percent $(\%)$ \\
\hline Long/heavy & 88 & 75.9 \\
Short/light & 28 & 24.1 \\
Total & 116 & 100.0 \\
\hline
\end{tabular}

Assessment of Factors Responsible for Road Traffic Delay

Drivers' Assessment of Bad Roads as a Cause of Traffic Delay

As shown in Table 3, 47 drivers representing $40.4 \%$ of total respondents strongly asserted road traffic delay on this road to be as a result of bad roads. 33 drivers out of 116 , representing $28.5 \%$ agreed to bad roads being the cause of traffic delay. $7.8 \%$ of drivers moderately agreed that the state of the road is the cause of traffic delay, while $23.3 \%$ disagreed to this fact. The data in the table showed $68.9 \%$ of drivers attributing the cause of road traffic delay to bad roads i.e. $68.9 \%$ agreed that the traffic delay resulted from bad roads, while $23.3 \%$ disagreed to this, and attributed traffic delay to other factors. This implies that bad roads influence traffic delay on this road, since majority of drivers attributed traffic delay to this factor.

Drivers' Assessment of Reckless Driving as a Cause of Traffic Delay

Results showed in Table 3 that respondents' assessment of reckless driving is one of the causes of traffic delay on this road as $32.8 \%$ of the sampled population strongly agreed to the factor, while a $26.7 \%$ agreed moderately, making a total of $59.5 \%$ attesting affirmative to reckless driving of drivers as a causative factor of traffic delay along Lagos-Abeokuta expressway.
This suggested that reckless driving to a great extent affects the traffic situation on this road.

Drivers' Assessment of Volume of Traffic as a Cause of Traffic Delay

The study revealed in Table 3 that assessment of 'volume of traffic' as a cause of traffic delay had 22 respondents who strongly disagreed; 33 respondents disagreed; 3 moderately agreed, 26 agreed and 32 strongly agreed. The study found that most respondents agreed to this factor as one of the causes with driver's agreement index (DAI) of 3.11.

Drivers' Assessment of Accident as a Cause of Traffic Delay

As shown in Table 3, the study revealed in that 'accident' occurrence as a cause of traffic delay revealed 49 respondents who strongly disagreed; 23 respondents who disagreed; 38 respondents, who moderately agreed, 5 respondents, who agreed and 1 respondent, who strongly agreed. The study found that most respondents disagreed with the factor as one of the causes with DAI value of 2.01.

Drivers' Assessment of Presence of Many Heavy Duty Vehicles as a Cause of Traffic Delay

As shown in the results, the study revealed that the 'Presence of many heavy duty vehicles' as a cause of traffic delay had 93 respondents who strongly disagreed; 12 respondents who disagreed; 
2 respondents, who moderately agreed, 6 respondents, who agreed and 3 respondents, who strongly agreed. Respondents' opinion showed that the presence of heavy duty trucks does not pose an injurious traffic challenge in the study area with $90.4 \%$ disagreeing to this fact. The study found that most respondents disagreed with the factor as one of the causes with DAI value of 1.40.

Drivers' Assessment of Vehicle Breakdown as a Cause of Traffic Delay

The study found that "vehicles breakdown' as a cause of traffic delay had 98 respondents who strongly disagreed; 13 respondents who disagreed; 5 respondents, who moderately agreed, 2 respondents, who agreed and 0 respondent, who strongly agreed. The study found that most respondents disagreed with the factor as one of the causes with a DAI value of 1.27.

Drivers' Assessment of Flooding as a Cause of Traffic Delay

As shown in Table 4, the study revealed that 'Flooding' occurrence as a cause of traffic delay depicted 111 respondents who strongly disagreed; 13 respondents who disagreed; 0 respondent, who moderately agreed, 2 respondents, who agreed and 0 respondent, who strongly agreed. The study found that most respondents disagreed with the factor as one of the causes with a DAI value of 1.25 .

Drivers' Assessment of Presence of Intersections as a Cause of Traffic Delay

The study found that 'presence of intersections' as a cause of traffic delay had 100 respondents who strongly disagreed; 13 respondents who disagreed; 3 respondents, who moderately agreed, 0 respondents, who agreed and 0 respondent, who strongly agreed. The study found that most respondents disagreed with the factor as one of the causes with a DAI value of 1.16.

Drivers' Assessment of Bad weather as a Cause of Traffic Delay

As shown in Table 3, the study revealed that 'Bad weather' occurrence as a cause of road traffic delay showed 101 respondents who strongly disagreed; 15 respondents who disagreed; 0 respondent, who moderately agreed, 0 respondent, who agreed and 0 respondent, who strongly agreed. The study found that most respondents disagreed with the factor as one of the causes with a DAI value of 1.13 .

Drivers' Assessment of Faulty Traffic Signal as a Cause of Traffic Delay

The study found that 'Faulty traffic signal' is a cause of traffic delay as 109respondents strongly disagreed; 3 respondents disagreed; 1 respondent moderately agreed, 2 respondents agreed and 0 respondent strongly agreed. The study found that most respondents disagreed with the factor as one of the causes with a DAI value of 1.12 .

Drivers' Assessment of Pedestrian Crossing as a Cause of Traffic Delay

As shown in Table 3, the study revealed that 'Pedestrian crossing' as a cause of traffic delay entailed 112 respondents, who strongly disagreed; 0 respondent, who disagreed; 2 respondents, who moderately agreed, 2 respondents, who agreed and 0 respondent, who strongly agreed. The study found that most respondents disagreed with the factor as one of the causes with a DAI value of 1.03 .

Likert's Scale Output of Drivers' Assessment of Causes of Traffic Delay

Results in Table 3 further revealed the sum of weighted value (SWV) of 
drivers' assessment of the causes of traffic delay in order of intensity of effect. The columns show the arrangement of factors responsible for traffic delay according to degree of influence. Factors are arranged along the columns such that, the higher the values in a column, the clearer the factors causing traffic delay in the study area. For instance, indiscreet use of bus stops and bad road condition are more dominant factors causing traffic delay in the study. The study estimated 12 as the variance and 0.005776 was taken as the standard deviation. The study established the co-efficient of variation as 0.273.

Table 3: Drivers' Assessment Indices of Causes of Road Traffic Delay

\begin{tabular}{|c|c|c|c|c|c|c|c|}
\hline Causes & $\mathrm{SD}_{1}$ & $\mathrm{D}_{2}$ & $\mathrm{MA}_{3}$ & $\mathrm{~A}_{4}$ & $\mathrm{SA}_{5}$ & SWV & DAI \\
\hline $\begin{array}{l}\text { Indiscreet use of Bus- } \\
\text { Stops }\end{array}$ & 0 & 1 & 4 & 24 & 87 & 545 & 4.70 \\
\hline Bad Roads & 11 & 16 & 9 & 33 & 47 & 437 & 3.77 \\
\hline Drivers' Recklessness & 16 & 27 & 4 & 31 & 38 & 396 & 3.41 \\
\hline Volume of Traffic & 22 & 33 & 3 & 26 & 32 & 361 & 3.11 \\
\hline Accidents & 49 & 23 & 38 & 5 & 1 & 234 & 2.01 \\
\hline $\begin{array}{l}\text { Presence of Many Heavy } \\
\text { duty vehicles }\end{array}$ & 93 & 12 & 2 & 6 & 3 & 162 & 1.40 \\
\hline Vehicle Breakdowns & 98 & 13 & 5 & 2 & 0 & 147 & 1.27 \\
\hline Flooding & 111 & 13 & 0 & 2 & 0 & 145 & 1.25 \\
\hline Intersections & 100 & 13 & 3 & 0 & 0 & 135 & 1.16 \\
\hline Bad Weather & 101 & 15 & 0 & 0 & 0 & 131 & 1.13 \\
\hline Faulty Traffic Signal & 109 & 3 & 1 & 3 & 0 & 130 & 1.12 \\
\hline Pedestrian Crossing & 112 & 0 & 2 & 2 & 0 & 126 & 1.09 \\
\hline Total & & & & & & & 25.42 \\
\hline
\end{tabular}

The variance, standard deviation and co-efficient of variance of drivers' responses are as estimated below;

$$
\begin{gathered}
\text { Variance }\left(S^{2}\right)=\sum[\mathrm{DAI}-\mathrm{MDAI}]^{2} \\
=\frac{(0.02)^{2}}{12}=\frac{0.0004}{12} \\
=0.0000333333
\end{gathered}
$$

Standard deviation $(\mathrm{SD})=\sqrt{ }$ Variance

$$
=\sqrt{ } 0.00003333=0.005776
$$

Co-efficient of variation $=[(\mathrm{SD} / \mathrm{MDAI}) \times 100] \%$

$=[(0.0058 / 2.12) \times 100] \%=(0.0027 \times 100)=0.273$

\section{Estimation of Man Hour Loss}

The study showed the estimate loss in man-hour due to road traffic delay in the study area. As shown in Table 4, 12.9\% of respondents were delayed for 10-15 minutes daily; 51 respondents representing $44 \%$ spent between 20-45 minutes; 21 respondents representing 
$18.1 \%$ spent 1 hour as average daily delay time; 28 respondents representing $44.1 \%$ spent 2 hours while 1 respondent representing $0.9 \%$ spent above 3 hours in delay.

Table 5: Time spent in traffic (Average Daily Loss of man-hour)

\begin{tabular}{lll}
\hline Time & Frequency & Percent $(\%)$ \\
\hline $10-15$ mins & 15 & 12.9 \\
$20-45$ mins & 51 & 44.0 \\
1 hour & 21 & 18.1 \\
2 hours & 28 & 24.1 \\
3 hours and above & 1 & 0.9 \\
Total & 116 & 100.0 \\
\hline
\end{tabular}

\section{Estimated Accumulated Loss of Man-} Hour Due to Traffic Delay

As shown in Table 4, the delay time duration (man hour loss) of drivers was computed to show the estimated accumulated loss of man hour as well as daily man hour loss on the study road.

The implication of this is that $13 \%$ of drivers on this road lose a minimum of 3 days, 19 hours, 15 minutes (91.25 man hours) annually to traffic delay. A further $44 \%$ of drivers who use this road loose at least a total of 11 days, 10 hours (273.75 man hours) every year to traffic delay. Also, $18 \%$ of drivers experienced a time loss of at least 19 days, 15 minutes
(456.25 man hours) annually, while $24 \%$ experienced a loss of 34 days, 5 hours, 15 minutes (821.25 man hours). $1 \%$ of drivers spent at least an average of 53 days, 5 hours, 30 minutes $(1,277.5$ man hours) in traffic every year.

From this data, it can be estimated that a total of 2,920 man hours (121 days, 16 hours) is lost annually on this road due to congestion and traffic delay. The daily accumulated estimate for man hour loss is given as 8 hours per day. This gives the average daily man hour loss as 1.6 man hours (1 hour 36 minutes) for all drivers along this road, subject to peak periods of 7a.m. - 10a.m., and 5p.m. - 8p.m. daily.

Table 6: Estimated accumulated loss of man hour due to traffic delay (in hours)

\begin{tabular}{llllll}
\hline Time loss & Percent & Daily & Weekly & Monthly & Annually \\
\hline $10-15$ mins & 13 & 0.25 & 1.75 & 7.5 & 91.25 \\
$20-45$ mins & 44 & 0.75 & 5.25 & 22.5 & 273.75 \\
1 hour & 18 & 1.25 & 8.75 & 37.5 & 456.25 \\
2 hours & 24 & 2.25 & 15.75 & 67.5 & 821.25 \\
3 hours & 1 & 3.5 & 24.5 & 105 & $1,277.5$ \\
Total & 100 & 8 & 56 & 240 & 2,920 \\
\hline
\end{tabular}

Conclusion and Recommendations

In conclusion, traffic delay is an inevitable aspect of sustainable development in cities. However, this study has examined the factors influencing road traffic delay through drivers' perspectives and loss of manhour along Lagos-Abeokuta Expressway, Lagos, Nigeria. This study estimated a total of 2,920 loss of man-hours annually. 
The daily accumulated estimate for man hour loss is given as 8 hours per day. This gives the average daily man hour loss as 1.6 man hours for all drivers along this road, subject to peak periods of 7a.m. - 10a.m., and 5p.m. - 8p.m. daily.

A rehabilitation/repair of deplorable portions of the road is needed to ensure free traffic flow, especially on the portions with bad road condition. This measure is needed in areas such as Abule-egba and Toll-gate. A strict enforcement of road rules and regulations, which can be done by the mounting of check points at traffic hotspots to correct defaulting drivers is also needed. There should be a development/improvement of alternative means of transportation in the area (i.e. rail transport) as the current state of the rail transport should be improved upon to standard.

Since field observation noted this fact in areas such as Ikeja-along, Iyanadopemu, Iyana-ipaja, Abule-egba and Toll gate, measures such as the introduction of traffic monitoring personnel such as LASTMA to organize bus stop usage and proper parking of passenger buses stopping at bus stops to disengage, or pick up passengers and ensure there are no traffic gridlocks; Introduction of no-stopping policies along the expressway, and the strict penalization of defaulting drivers making unauthorized stops at undesignated points, thereby causing impedance to free flow of traffic. There is a need for the expansion of the road to meet present and future transportation demands as traffic will continue to build on this road due to expansion and urban development. The use of high capacity mass transit vehicles should be more encouraged rather than low carrying capacity mass transit vehicles. This will reduce the burden of usage on the road and save time for drivers and commuters. There is a need to create designated bus parks for commercial buses to avoid congestion at bus stops.

\section{References}

Adedimila, A.S. (1981). "Towards improving traffic flow in Lagos", In Onakomaiya S.O. and Asiyanbola, R.A., Osoba, S.B. and Adewale, S.S. (2012). "Road traffic administration and management in the third world mega-city: Lagos, Nigeria", International Journal of Development and Sustainability, 1(2): 490-509.

Banjo, G.A. (1984). Towards a New Framework for Urban Transport Planning in Third World Cities. Proceeding Australian Road Research Board Conference, 12(1):

Ciccone, A. and Hall, R. (1996). Productivity and density of economic activity." The American Economic Review, 86(1): 54-70.

Olak, S., Lima, A.and Gonzalez, M.C. (2016). Understanding congested travel in urban areas. Nature Communications 7, Article number: 10793

Downs, A. (2004). Still stuck in traffic: Coping with peak-hour traffic congestion. Brookings Institution Press.

Eddington, R. (2006). The Eddington Transport Study Main Report: Transport's role in sustaining the UK's Productivity and Competitiveness. UK Department for Transport, London. Retrieved from 
www.dft.gov.uk/about/strategy/tran sportstrategies/eddingtonstudy.

Mabrouk, A. and Abdennadher, C. (2016). Estimation of Time Loss and Costs of Traffic Congestion: The Contingent Valuation Method. World Academy of Science, Engineering and Technology. International Journal of Social, Behavioural, Educational, Economic, Business and Industrial Engineering, 10(3):

Olagunju, K. (2013). Evaluating traffic congestion in developing countriesCase study of Nigeria. 2015. Federal Road Safety Corps, Nigeria

LASMEPB (2013). The Socio-economic Costs of Traffic Congestion in Lagos. (July, 2013).

Odeleye, J.A. (2008). A study of Road Traffic Congestion in selected Corridors of Metropolitan Lagos.

Oni, S.I. (1992). Car park provision and planning in metropolitan Lagos. Unpublished thesis, department of urban and regional planning, University of lagos.

Ortuzar J. D and Willumsen, N. (1990). 'Modeling Transport, Wiley Publishers (NY), USA.

Oyesiku. O. (2002). From Womb to Jomb 24th Inaugural Lecture, Olabisi Onabanjo University, AgoIwoye, 27th August 2002.

Rodrigue, Jean-Paul (2013). The Geography of Transport Systems. Routledge Publishers, New York. ISBN 978-0-415-82254-1

United Nations Settlement Programme (UN-Habitat), (2012). Nigeria: Ifako-Ijaiye Urban Profile

Wang, P., Hunter, T., Bayen, A.M., Schechtner, K. and Gonzalez, M.C. (2012). Understanding Road Usage Patterns in Urban Areas. Scientific Reports; a nature research journal, Article number: 1001 (2012). Retrieved from http://www.nature.com/articles/srep $\underline{01001}$ 